\title{
The Nexus between Workplace Exposure for Wood, Welding, Motor Mechanic, and Oil Refinery Workers and the Prevalence of Prediabetes and Type 2 Diabetes Mellitus
}

\author{
Sultan Ayoub Meo*(1), Thamir Al-khlaiwi, Abdulelah Adnan Abukhalaf, Ali Abdullah Alomar, \\ Omar Mohammed Alessa, Faris Jamal Almutairi and Majed Mohammed Alasbali \\ Department of Physiology, College of Medicine, King Saud University, Riyadh 11461, Saudi Arabia; \\ talkhlaiwi@ksu.edu.sa (T.A.-k.); Abdulelahabukhalaf@gmail.com (A.A.A.); AliAlomarMD@gmail.com (A.A.A.); \\ omar.m.alessa@gmail.com (O.M.A.); Faris11300@gmail.com (F.J.A.); Majedalasbaly@gmail.com (M.M.A.) \\ * Correspondence: smeo@ksu.edu.sa
}

Received: 18 May 2020; Accepted: 30 May 2020; Published: 4 June 2020

\begin{abstract}
Workplace exposure in various occupational and industrial sectors is an emerging health concern worldwide. This study aimed to investigate the nexus between workplace exposure for wood, welding, motor mechanic, and oil refinery workers and the prevalence of prediabetes and type 2 diabetes mellitus. Initially, 2500 male volunteers who were wood, welding, motor mechanic, and oil refinery workers were interviewed. After an examination of their demographics and medical history, 1408 non-smoking wood (158), welding (560), motor mechanic (272), and oil refinery workers (217), along with 201 control subjects, were selected. The participants' mean age was $36.59 \pm 0.29$ years and the mean body mass index was $26.14 \pm 0.11 \mathrm{~kg} / \mathrm{m}^{2}$. The selected industry workers had been exposed to their respective wood, welding, motor mechanic, and oil refinery workplaces for $8 \mathrm{~h}$ per day, six days per week. The American Diabetic Association (ADA)-based glycated hemoglobin $(\mathrm{HbA1c})$ criterion was used to diagnose prediabetes and type 2 diabetes mellitus. Subjects with an $\mathrm{HbA} 1 \mathrm{c}$ of less than $5.7 \%$ were regarded as non-diabetics, subjects with an $\mathrm{HbA} 1 \mathrm{c}$ of $5.7-6.4 \%$ were considered prediabetics, and subjects with an $\mathrm{HbA} 1 \mathrm{c}$ of more than $6.4 \%$ were considered diabetics. In wood industry workers, the prevalence of prediabetes (PD) was $64(40.50 \%)$ and in type 2 diabetes mellitus (T2DM), it was 21 (13.29\%); in welding workers, the prevalence of prediabetes was 261 $(46.60 \%)$, and for T2DM, it was $90(16.07 \%)$; in motor mechanic workers, the prevalence of prediabetes was $110(40.44 \%)$, and for T2DM, it was $126(46.32 \%)$; and in oil refinery workers, the prevalence of prediabetes was $80(36.86 \%)$, and for T2DM, it was 35 (16.12\%). However; the combined prevalence of prediabetes and T2DM among wood, welding, motor mechanic, and oil refinery workers was $421(34.79 \%)$ and $515(42.66 \%)$, respectively. The prevalence of prediabetes and T2DM among workers increased with the duration of working exposure in the wood, welding, motor mechanic, and oil refinery industries. A one-year working exposure in these industries caused an increase of $0.03 \%$ in $\mathrm{HbA1c}$. Workplace exposure in wood, welding, motor mechanic, and oil refinery industries increased the risk of prevalence of prediabetes and T2DM among the workers and affected the diabetes etiology.
\end{abstract}

Keywords: environmental pollution; workplace; prevalence; type-2 diabetes mellitus

\section{Introduction}

Diabetes mellitus is a leading health concern worldwide with a growing occurrence and numerous long-lasting complications. Despite many incredible advancements in medical sciences, diabetes mellitus is still an incurable life-long disease. It is rapidly occurring in all age and gender 
clusters [1], in both developing and developed nations, and rural and urban regions across the globe. It involves and impairs various physiological functions, organs of the body, and body systems [1], with widely ranging disastrous health problems [2].

The most recent prevalence of diabetes mellitus is 463 million people, and 232 million people are unaware of the fact that they are suffering from the disease. A total of 310 million people with diabetes are living in urban areas, while 153 million people are residing in rural areas. Furthermore, 327 million people with diabetes, i.e., about three-quarters of those with diabetes, are of working age and 366 million diabetic people live in low-income and middle-income countries [3]. Diabetes mellitus currently ranks high on the international health agenda due to it being a major global issue that significantly harms human health and worldwide economies [4]. Many countries across the globe have developed strategies to intervene regarding behavioral risk factors, such as lifestyle, smoking, diet, fast food culture, and physical activity, to reduce the prevalence of diabetes. However, occupational-related environmental pollution has received noticeably less attention from intervention efforts [5].

The global total population is 7.594 billion and the population of labor workers is 3.489 billion people [6]. In 2019, the World Health Organization [7] reported that 70\% of workers do not have any insurance for compensation in the case of occupational diseases or injuries. The air pollution in both rural and urban areas has been estimated to cause 4.2 million premature deaths worldwide, mainly in low-income and middle-income countries [7].

Occupational exposure to pollutants generated from industries, including wood [8], welding [9], motor mechanic, and oil refinery [10] industries, is an emerging environmental risk factor that is contributing to the development of acute and chronic diseases. Workers in industrial sectors are exposed to various toxic substances, including fine particulate matter [11]. Particulate matter (PM $2.5 \mu \mathrm{m})$ is one of the main pollutants and concerns about it have been increasing because of its damaging impact on human health [12], which is due to its complex composition and wide distribution. The effects of PM on health depend on its size, nature, and chemical composition [13]. Airborne fine particulate matter with an aerodynamic diameter of PM $2.5 \mu \mathrm{m}$ can penetrate deep into the lungs and gastrointestinal tract (GIT), and pass through the lung and GIT barrier to enter circulating blood. PM $2.5 \mu \mathrm{m}$ comes from a broad range of chemical and biological sources [13], including nitrogen dioxide, sulfur dioxide, nitrate, ammonium, and organic compounds, as well as polycyclic aromatic hydrocarbons, dust, fumes, and metals [14]. Experimental and epidemiologic studies give support to the concept that work-related exposure to dust and fumes has harmful effects on many biological systems, including the respiratory [15], cardiovascular [16,17], and nervous systems [18].

In recent years, evidence has been accumulating showing that workplace exposure to various occupational and industrial sectors can adversely affect human health $[19,20]$. However, the literature available right now is mainly based on animal model studies, while human model studies have not been conducted on the workplace exposure in wood, welding, motor, and oil refinery industries and its association with type 2 diabetes mellitus (T2DM). This study aimed to investigate the nexus between workplace exposure in wood, welding, motor mechanic, and oil refinery industries and the prevalence of prediabetes and type 2 diabetes mellitus.

\section{Subjects and Methods}

\subsection{Study Participants}

In this study, the workers from four industries-wood, welding, motor mechanic, and oil refinery-were selected from the Riyadh region, Saudi Arabia. Initially, 2500 male volunteers from these four industries were interviewed, and after demographic and medical history examinations, 1408 non-smoking wood (158), welding (560), motor mechanic (272), and oil refinery (217) workers, along with control subjects (201), were selected. The mean age for the participants was $36.59 \pm 0.29$ years and the mean body mass index was $26.14 \pm 0.11 \mathrm{~kg} / \mathrm{m}^{2}$. The wood, welding, motor mechanic, and oil refinery workers were exposed to concerning industry pollution for $8 \mathrm{~h}$ per day, six days 
per week. It was ensured that these workers only worked in these four industries and were not exposed to other industries, such as plastic, cement, coal, cotton, or flour factories. The non-smoking control subjects (201) were selected from schools and university clerical staff, technicians, and research assistants. Verbal consent was taken from all the participants who had voluntarily registered to join the research project.

\subsection{Clinical History and Sociodemographic Characteristics}

Three co-investigators interviewed 2500 volunteer male workers and detailed sociodemographic and medical information was obtained. The baseline information, including age, gender, height, weight, BMI, duration of exposure, demographic characteristics, lifestyle, and other health-related information was collected from the questionnaire. Demographic characteristics, including residential address, living conditions, education level, marital status, monthly income, lifestyle information, smoking, and physical activity were recorded. Other health-related evidence, including a family history of diabetes mellitus, was also taken. After demographic, medical history and examination investigations, 1408 non-smoking wood (158), welding (560), motor mechanic (272), and oil refinery (217) workers, along with the control subjects (201), were selected.

\subsection{Exclusion Criteria}

The participants with a known history of anemia, blood diseases, blood transfusion, asthma, diabetes mellitus, and malignancy were excluded from the study. Subjects with marked obesity were also excluded to minimize the impact of obesity on the prevalence of prediabetes and type 2 diabetes mellitus. The workers who smoked traditional or electronic cigarettes, or shisha, were also excluded [21]. It was ensured that these workers only worked in the wood, welding, motor mechanic, and oil refinery industries. Subjects with a previous history of employment in any other industrial plant that produces dust or fumes, such as plastic, cement, coal, cotton, and flour factories, were also not included in the study [22] (Figure 1).

\subsection{Measurements of Glycated Hemoglobin (HbA1c)}

After a detailed medical interview and gathering demographic data, the selected industry workers were assigned an identification number and a trained paramedic was assigned to measure the $\mathrm{HbA} 1 \mathrm{c}$. The HbA1c was measured using the Clover A1c system (Inforpia, Kyunggi, Korea), which is an automated boronate affinity assay for the determination of the HbA1c percentage in whole blood [23]. The American Diabetic Association (ADA)-based criteria [24] regarding glycated hemoglobin (HbA1c) was used to diagnose diabetes mellitus. Subjects with an $\mathrm{HbA1c}$ of less than 5.7\% were considered non-diabetics, an $\mathrm{HbA} 1 \mathrm{c}$ of $5.7-6.4 \%$ were considered prediabetics, and subjects with an $\mathrm{HbA} 1 \mathrm{c}$ of more than $6.4 \%$ were considered diabetics [24]. HbA1c is a highly reliable and valid indicator of long-lasting glycemic measurements for the diagnosis of diabetes mellitus [24,25].

\subsection{Ethics Statement}

This study was executed in harmony with the "Declaration of Helsinki," and the protocol was approved by the Institutional Review Board, Ethics Committee, College of Medicine Research Centre, King Saud University (E-18-3654).

\subsection{Statistical Analysis}

The data were entered into the computer, where the IBM SPSS Version 22 and Microsoft Windows software, Armonk, NY, USA were used. Continuous variables were expressed as the mean \pm standard deviation and descriptive data were expressed as frequency (\%). The frequencies and percentages for the prevalence of prediabetes and type 2 diabetes mellitus, their association with sociodemographic data, and the duration of exposure were calculated using chi-square tests of independence. To identify 
the independent risk factor for HBA1c, a multiple linear regression model was used. The level of significance was taken to be $p<0.05$.

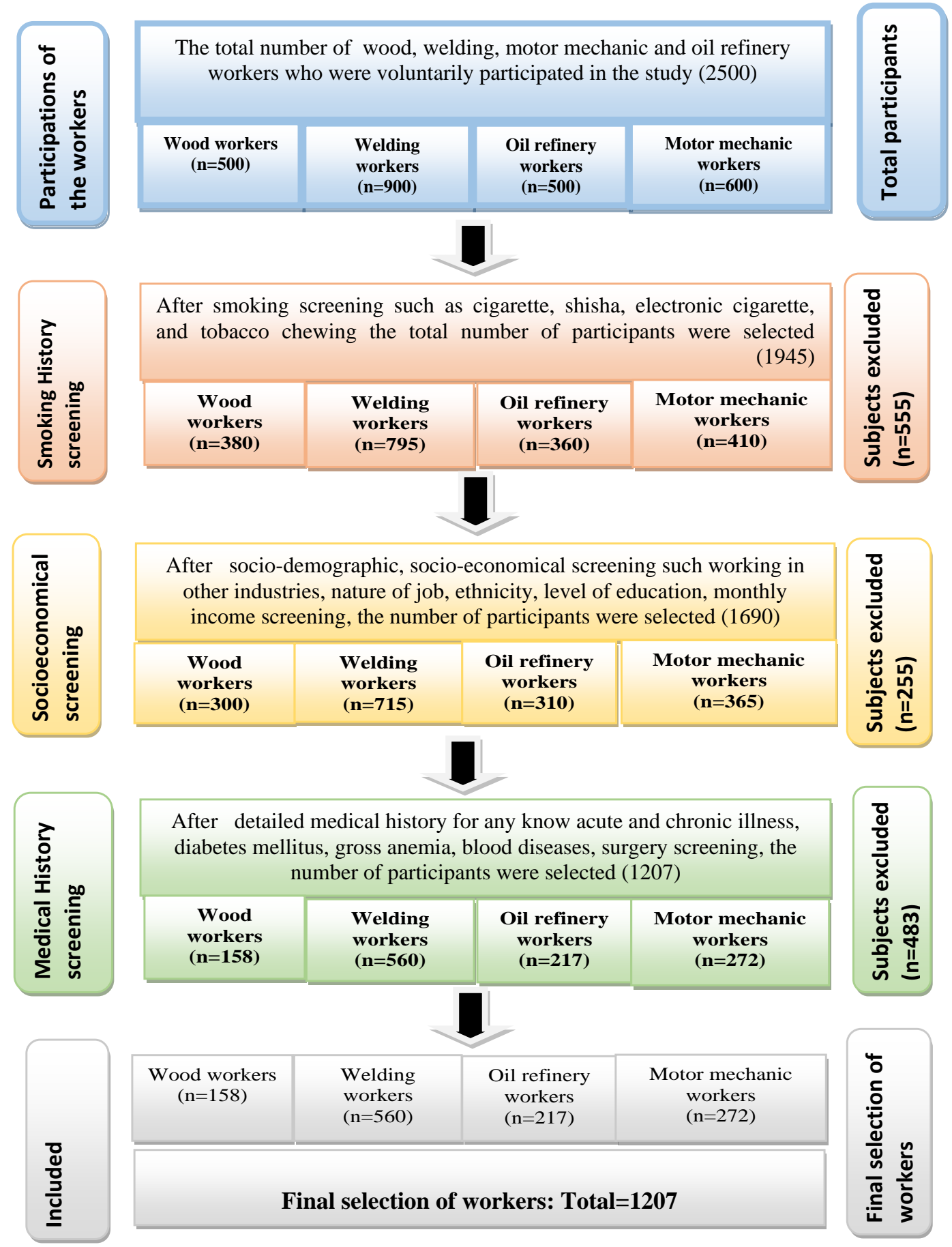

Figure 1. Flow diagram of the selection of wood, welding, motor mechanic, and oil refinery workers.

\section{Results}

The anthropometric features of the wood, welding, motor mechanic, and oil refinery workers, as well as the control group, are presented in Table 1 . The mean age for the participants was $36.59 \pm 0.29$ years and the mean body mass index was $26.14 \pm 0.11 \mathrm{~kg} / \mathrm{m}^{2}$. These workers were exposed in the wood, welding, motor mechanic, and oil refinery industries for $8 \mathrm{~h}$ daily, six days a week. The mean duration of exposure to these industries was 8.41 years (Table 1). 
Table 1. Sociodemographic and clinical characteristics of wood, welding, motor mechanic, and oil refinery workers, as well as the control group $(n=1408)$.

\begin{tabular}{cccccc}
\hline Variables & $\begin{array}{c}\text { Wood } \\
\text { Workers } \\
(\boldsymbol{n}=\mathbf{1 5 8})\end{array}$ & $\begin{array}{c}\text { Welding } \\
\text { Workers } \\
(\boldsymbol{n}=\mathbf{5 6 0})\end{array}$ & $\begin{array}{c}\text { Motor Mechanic } \\
\text { Workers } \\
(\boldsymbol{n}=\mathbf{2 7 2})\end{array}$ & $\begin{array}{c}\text { Oil } \\
\text { Refinery Workers } \\
(\boldsymbol{n}=\mathbf{2 1 7})\end{array}$ & $\begin{array}{c}\text { Control } \\
\text { Group } \\
(\boldsymbol{n}=\mathbf{2 0 1})\end{array}$ \\
\hline Age (years) & $41.23 \pm 9.76$ & $35.41 \pm 9.49$ & $35.67 \pm 10.46$ & $37.0 \pm 10.64$ & $31.38 \pm 6.40$ \\
\hline BMI (kg/m2) & $25.30 \pm 3.14$ & $25.45 \pm 3.45$ & $26.57 \pm 4.53$ & $27.34 \pm 4.71$ & $24.88 \pm 2.36$ \\
\hline Exposure (years) & $10.47 \pm 0.87$ & $6.68 \pm 6.56$ & $14.42 \pm 8.98$ & $1.00 \pm 0.80$ & - \\
\hline HbA1c $(\%)$ & $5.70 \pm 0.86$ & $5.98 \pm 0.98$ & $7.25 \pm 2.02$ & $6.09 \pm 1.42$ & $5.39 \pm 0.46$ \\
\hline
\end{tabular}

In the wood industry workers, the prevalence of prediabetes was $64(40.50 \%)$ and for T2DM, it was $21(13.29 \%)$; in welding workers, the prevalence of prediabetes was $261(46.60 \%)$ and for T2DM, it was 90 (16.07\%); in motor mechanic workers, the prevalence of prediabetes was $110(40.44 \%)$ and for T2DM, it was 126 (46.32\%); and among oil refinery workers, the prevalence of prediabetes was 80 $(36.86 \%)$ and for T2DM, it was $35(16.12 \%)$ (Table 2$)$. Among the workers, the association of prediabetes and T2DM was linked with the working duration in these industries (Table 3). However, there was no relationship identified between BMI and the prevalence of prediabetes or T2DM among the industry workers (Table 3).

Table 2. Prevalence of prediabetes and type 2 diabetes mellitus among wood, welding, motor mechanic, and oil refinery workers $(n=1207)$.

\begin{tabular}{|c|c|c|c|c|c|}
\hline \multirow{2}{*}{ Parameters } & \multicolumn{5}{|c|}{ Prevalence of Prediabetes and Type 2 Diabetes Mellitus } \\
\hline & $\begin{array}{c}\text { Wood } \\
\text { Workers } \\
(n=158)\end{array}$ & $\begin{array}{l}\text { Welding } \\
\text { Workers } \\
(n=560)\end{array}$ & $\begin{array}{l}\text { Motor Mechanic } \\
\text { Workers } \\
(n=272)\end{array}$ & $\begin{array}{l}\text { Oil Refinery } \\
\text { Workers } \\
(n=217)\end{array}$ & $\begin{array}{l}\text { Combined } \\
\text { Prevalence } \\
(n=1207)\end{array}$ \\
\hline $\begin{array}{c}\text { Normal: } \\
\text { HbA1c }<5.7 \%\end{array}$ & $73(46.20 \%)$ & $\begin{array}{c}209 \\
(37.23 \%)\end{array}$ & $36(13.23 \%)$ & $102(47.00 \%)$ & $420(34.79 \%)$ \\
\hline $\begin{array}{c}\text { Prediabetes: } \\
\text { HbA1c } \\
5.7-6.4 \%\end{array}$ & $64(40.50 \%)$ & $\begin{array}{c}261 \\
(46.60 \%)\end{array}$ & $110(40.44 \%)$ & $80(36.86 \%)$ & $515(42.66 \%)$ \\
\hline $\begin{array}{c}\text { Diabetes: } \\
\text { HbA1c }>6.4 \%\end{array}$ & $21(13.29 \%)$ & $90(16.07 \%)$ & $126(46.32 \%)$ & $35(16.12 \%)$ & $272(22.53 \%)$ \\
\hline
\end{tabular}

Table 3. Multiple regression analysis for $\mathrm{HbA} 1 \mathrm{c}$ between subjects exposed in wood, welding, motor mechanic, and oil refinery industries, as well as the control group $(n=1408)$.

\begin{tabular}{ccccccc}
\hline Covariate & Level & B & $\begin{array}{c}\mathbf{9 5 \%} \text { CI } \\
\text { Low }\end{array}$ & $\begin{array}{c}\text { HbA1c } \\
\mathbf{9 5 \%} \text { CI } \\
\text { High }\end{array}$ & $\begin{array}{c}\text { Type B } \\
p \text {-Value }\end{array}$ & $\begin{array}{c}\text { Type 3 } \\
\boldsymbol{p} \text {-Value }\end{array}$ \\
\hline Group & Motor mechanic & 1.71 & 1.48 & 1.93 & $<0.001$ & \\
& Oil & 0.47 & 0.23 & 0.71 & $<0.001$ & \\
& Welding & 0.46 & 0.27 & 0.66 & $<0.001$ & $<0.001$ \\
& Wood & 0.20 & -0.06 & 0.46 & 0.138 & \\
Duration & Control & - & - & - & - & \\
BMI & One-year increase & 0.03 & 0.02 & 0.04 & $<0.001$ & $<0.001$ \\
\hline \multicolumn{2}{r}{ B-Regression coefficient; type B $p$-value: overall association; type 3 $p$-value: overall association. }
\end{tabular}

B-Regression coefficient; type B $p$-value: overall association; type $3 p$-value: overall association. 
The combined prevalence of prediabetes and T2DM among wood, welding, motor mechanic, and oil refinery workers was $420(34.79 \%)$ and $515(42.66 \%)$, respectively (Table 2$)$. The prevalence of prediabetes and T2DM among these workers was significantly increased with the duration of working exposure in these four industries. After adjustment for age and BMI, and based on the findings of a multiple regression analysis for HBA1c between the control and exposed subjects, it was found that the HBA1c was significantly higher among welding, motor mechanic, oil workers compared to the control group (Table 2). The one-year working exposure to these workers caused an increase of $0.03 \%$ in $\mathrm{HbA1c}$ (Table 3). It was also found that HBA1c was significantly higher among the workers in these four industries compared to BMI-matched control subjects (Table 3).

\section{Discussion}

To the best of our knowledge, this is the first study added in the medical literature that investigated the nexus between workplace exposure to the wood, welding, motor mechanic, and oil refinery industries and the prevalence of prediabetes and type 2 diabetes mellitus. In this study, a positive correlation was identified between the prevalence of prediabetes and T2DM and exposures to the wood, welding, motor mechanic, and oil refinery industries.

At the end of the 20th century, the overall understanding regarding the occurrence of type 2 diabetes mellitus was that it was due to eating unhealthy food, a lack of exercise, and genetics; however, in recent years, environmental pollution is becoming known as an emerging causative mechanism in the development of T2DM [26].

Paul et al. [27] found that air pollutants, especially nitrogen dioxide $\left(\mathrm{NO}_{2}\right)$, was linked to an increased risk of diabetes mellitus. As $\mathrm{NO}_{2}$ is frequently found in and near road traffic, this may indicate that traffic-related air pollution has a strong impact on diabetes etiology. In another study, Liu et al. [28] found that a higher residential exposure of air pollutant concentrations of PM $2.5 \mu \mathrm{m}$ and $\mathrm{NO}_{2}$ increased the odds of developing T2DM and high fasting blood glucose levels.

Similarly, Meo et al. [20] reported that the prevalence of prediabetes and T2DM among plastic industry workers was increased with the duration of working exposure in the plastic industry. In another study, Meo et al. [22] also found that cement industry pollution is linked with a prevalence of prediabetes and T2DM. Meo et al. [19] demonstrated that environmental pollution is a major cause of insulin resistance and the incidence of type 2 diabetes mellitus. Correspondingly, in the present study, the prevalence of prediabetes and T2DM was identified in wood, welding, motor mechanic, and oil refinery workers, which was associated with the duration of working exposure in these factories. However, no association was established between BMI and the prevalence of prediabetes and T2DM among these industry workers (Table 3).

Kelsall et al. [29] found similar findings, where they investigated the association between the risk of T2DM with various occupational and industrial working populations. Increased diabetes risks were found in various occupational groups who worked in industries compared to the office workers. The authors concluded that the blue-collar industry workers had a high diabetes risk. Similarly, Yang et al. [30] also reported a high correlation between metal workers and the risk of prediabetes and diabetes mellitus. In animal-model-based studies, Wang et al. [31], Balti et al. [32], Park and Wang [33], Eze et al. [34], and Bellou et al. [35] reported that prolonged exposure to higher concentrations of environmental air pollutants is significantly associated with an increased risk of type 2 diabetes mellitus. In the present study, we identified that exposure to wood, welding, motor mechanic, and oil refinery industries is associated with a high prevalence of prediabetes and T2DM.

\subsection{Pollutant Mechanisms That Cause Insulin Resistance and T2DM}

The epidemiologic and experimental literature acknowledges that environmental pollutants enhance the risk of insulin resistance and ultimately leads to type 2 diabetes mellitus (Figure 2). Air pollutants may contribute low-grade inflammation and oxidative stress [36-38], pancreatic disruptions [39], decreased insulin signaling, glucose metabolism impairment, insulin resistance, and type 2 diabetes 
mellitus [37,38] (Figure 2). These are the possible mechanisms allowing pollution to cause insulin resistance and the prevalence of prediabetes and T2DM.

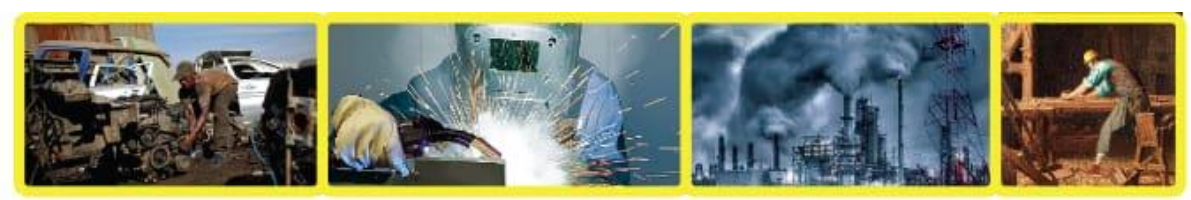

\section{Pollution}
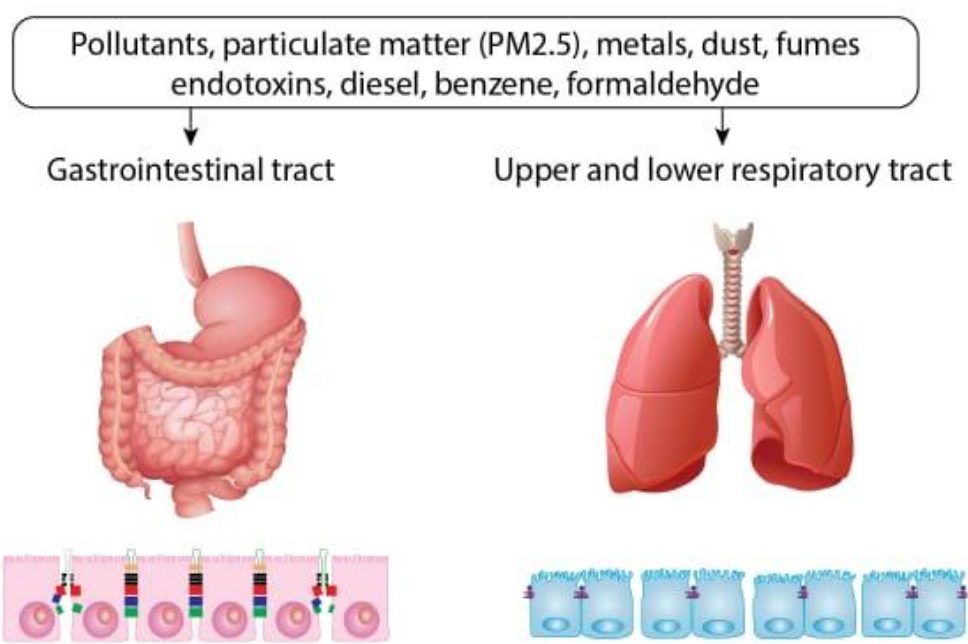

Breakdown of tight junction proteins and actomyosin network

Entry of particulate matter, chemicals, metabolites and inflammatory molecules into circulation

Effect on blood brain barrier permeability and the integrity of the neurovascular unit, damage to neuronal, glial and endothelial cells

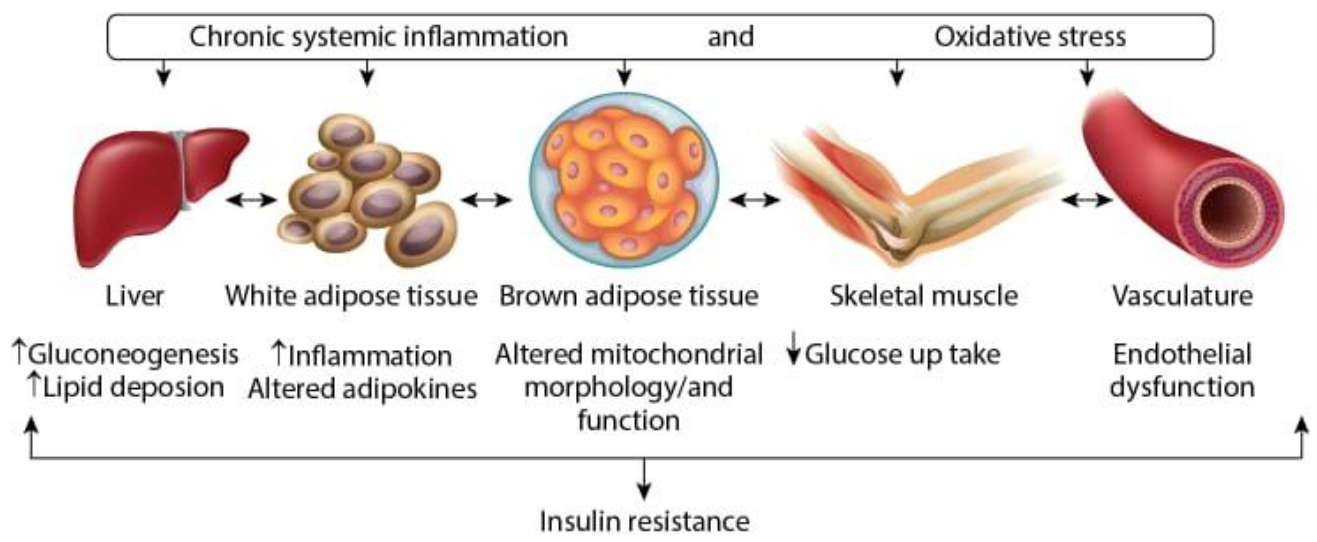

Figure 2. Mechanisms taking place during work exposure to pollutants and their entry into the human body that cause insulin resistance. UFPM: Ultrafine Particulate Matter.

\subsection{Study Strengths and Limitations}

Similar to other studies, this study has strengths and limitations. This is the first study to investigate the prevalence of prediabetes and T2DM among multi-industrial workers, including wood, welding, motor mechanic, and oil refinery industrial workers. The study exclusion criteria were highly 
standardized and cigarette smokers were excluded. The American Diabetes Association diagnosis approach was employed, which was based on $\mathrm{HbA1c}$ levels and all the participants were categorized as either normal, prediabetics, or diabetics. The glycated hemoglobin $(\mathrm{HbA} 1 \mathrm{c})$ is a more reliable and valid indicator for identifying an individual's long-term mean blood glucose levels. Therefore, this work could be considered a best reference regarding the industrial allied pollution and prevalence of prediabetes and T2DM since in this study, four different industries (wood, welding, motor mechanic, and oil refinery) were investigated.

However, the limitations in the present study are as follows: First, despite trying to recruit many workers from the wood, welding, motor mechanic, and oil refinery industries, the majority of employees were cigarette smokers; therefore, we excluded several workers and finally included 1207 workers. Second, we were unable to control for some potential confounders, such as indoor air pollution exposures, due to the unavailability of this information. The omission of these potential confounders may affect the extent that pollution has when potentially causing diabetes.

\section{Conclusions}

Workplace exposure in the wood, welding, motor mechanic, and oil refinery industries is associated with a high prevalence of prediabetes and T2DM. The prevalence was associated with the duration of working exposure in these occupational settings. The results indicate that wood, welding, motor mechanic, and oil refinery pollution affects diabetes etiology. The industry workers should wear respiratory protective equipment to minimize the risk of dust, fumes, and pollutant exposure. The working conditions have a powerful impact on health equity, and environmental health officials could provide important interventions for protecting workers' health, both in large- and small-scale industries to improve working conditions and provide early detection of occupationally caused prediabetes and T2DM among the workers. The present study's findings have significant public health implications as the findings support the extension of diabetes intervention efforts to include environmental risk factors that may contribute to diabetes etiology. Future prospective studies with broader geographic areas are still needed to further verify the present study's results and to confirm the correlation between work-produced pollutants and T2DM.

Author Contributions: S.A.M.: designed the study, applied for the research grant, and undertook the data analysis and manuscript writing. T.A.-k., A.A.A. (Abdulelah Adnan Abukhalaf), and A.A.A. (Ali Abdullah Alomar): sought ethics board approval and undertook the literature review and data collection. O.M.A., F..A., M.M.A.: undertook data collection and analysis. All authors have read and agreed to the published version of the manuscript.

Funding: Deanship of Scientific Research, King Saud University, Riyadh, Saudi Arabia, (RGP-VPP 181).

Acknowledgments: We thank the Deanship of Scientific Research, King Saud University, Riyadh, Saudi Arabia, for supporting the work through a research group project (RGP-VPP 181).

Conflicts of Interest: The authors declare no competing financial interests.

\section{References}

1. Meo, S.A. Diabetes mellitus: Health and wealth threat. Int. J. Diabet. Mellitus 2009, 1, 9. [CrossRef]

2. Wu, H.; Eggleston, K.N.; Zhong, J.; Hu, R.; Wang, C.; Xie, K.; Chen, Y.; Chen, X.; Yu, M. How do type 2 diabetes mellitus (T2DM)-related complications and socioeconomic factors impact direct medical costs? A cross-sectional study in rural Southeast China. BMJ Open 2008, 8, e020647. [CrossRef] [PubMed]

3. Internatinal Diabetic Fedration, diabetes atlas-9th edition. Available online: http://www.diabetesatlas.org/ key-messages.html (accessed on 12 February 2020).

4. Wang, Q.; Zhang, X.; Fang, L.; Guan, Q.; Guan, L.; Li, Q. Prevalence, awareness, treatment and control of diabetes mellitus among middle-aged and elderly people in a rural chinese population: A cross-sectional study. PLoS ONE 2018, 13, e0198343. [CrossRef] [PubMed]

5. World Health Organization. Protecting workers' health. Available online: https://www.who.int/news-room/ fact-sheets/detail/protecting-workers\%27-health (accessed on 12 February 2020). 
6. The World Bank. Available online: https://data.worldbank.org/indicator/SP.POP.TOTL (accessed on 12 February 2020).

7. World Health Organization. Ambient (outdoor) air pollution. Available online: https://www.who.int/newsroom/fact-sheets/detail/ambient- (accessed on 12 February 2020).

8. Meo, S.A. Lung function in Pakistani wood workers. Int. J. Environ. Health Res. 2006, 16, 193-203. [CrossRef]

9. Meo, S.A.; Azeem, M.A.; Subhan, M.M. Lung function in Pakistani welding workers. J. Occup. Environ. Med. 2003, 45, 1068-1073. [CrossRef]

10. Meo, S.A.; Alrashed, A.H.; Almana, A.A.; Altheiban, Y.I.; Aldosari, M.S.; Almudarra, N.F.; Alwabel, S.A. Lung function and fractional exhaled nitric oxide among petroleum refinery workers. J. Occup. Med. Toxicol. 2015, 10, 37. [CrossRef]

11. Estill, C.F.; Slone, J.; Mayer, A.; Chen, I.C.; Guardia, M.J. Worker exposure to flame retardants in manufacturing, construction and service industries. Environ. Int. 2019, 135, 105349. [CrossRef]

12. Liaoa, B.Q.; Liue, C.B.; Xiec, B.Q.; Liud, Y.; Denga, Y.B.; Hed, S.W. Effects of fine particulate matter (PM2.5) on ovarian function and embryo quality in mice. Environ. Int. 2019, 135, 105338. [CrossRef]

13. Oyewale, M.M.; Matlou, I.M.; Murembiwa, S.M.; Raymond, P.H. Health outcomes of exposure to biological and chemical components of inhalable and respirable particulate matter. Int. J. Environ. Res. Public Health 2016, 13, 10 .

14. Srimuruganandam, B.; Nagendra, S.M.S. Source characterization of $\mathrm{PM}_{10}$ and $\mathrm{PM}_{2.5}$ mass using a chemical mass balance model at urban roadside. Sci. Total Environ. 2012, 433, 8-19. [CrossRef] [PubMed]

15. Meo, S.A.; Al-Drees, A.M.; Al-Masri, A.A.; Al-Rouq, F.; Azeem, M.A. Effect of duration of exposure to cement dust on respiratory function of non-smoking cement mill workers. Int. J. Environ. Res. Public Health 2013, 10, 390-899. [CrossRef] [PubMed]

16. Meo, S.A.; Suraya, F. Effect of environmental air pollution on cardiovascular diseases. Eur. Rev. Med. Pharmacol. Sci. 2015, 19, 4890-4897. [PubMed]

17. Zhang, Z.; Dong, B.; Li, S.; Chen, G.; Yang, Z.; Dong, Y. Exposure to ambient particulate matter air pollution, blood pressure and hypertension in children and adolescents: A national cross-sectional study in China. Environ. Int. 2019, 128, 103-108. [CrossRef] [PubMed]

18. Oudin, A.; Frondelius, K.; Haglund, N.; Källén, K.; Forsberg, B.; Gustafsson, P.; Malmqvist, E. Prenatal exposure to air pollution as a potential risk factor for autism and ADHD. Environ. Int. 2019, 133, 105149. [CrossRef] [PubMed]

19. Meo, S.A.; Memon, A.N.; Sheikh, S.A.; Rouq, F.A.; Usmani, A.M.; Hassan, A.; Arian, S.A. Effect of environmental air pollution on type 2 diabetes mellitus. European Rev. Med. Pharmacol. Sci. 2015, 19, 123-128.

20. Meo, S.A.; AlMutairi, F.J.; Alasbali, M.M.; Alqahtani, T.B.; AlMutairi, S.S.; Albuhayjan, R.A.; Al Rouq, F.; Ahmed, N. Men's health in industries: Plastic plant pollution and prevalence of pre-diabetes and type 2 diabetes mellitus. Am. J. Mens Health 2018, 12, 2167-2172. [CrossRef]

21. Kim, J.H.; Noh., J.; ChoiM, J.W.; Park, E.C. Association of education and smoking status on risk of diabetes mellitus: A population-based nationwide cross-sectional study. Int. J. Environ. Res. Public Health 2017, 14, E655. [CrossRef]

22. Meo, S.A.; BinMuneif., Y.A.; BenOmran, N.A.; Alsadhan, M.A.; Hashem, R.F.; Alobaisi, A.S. Prevalence of Prediabetes and Type 2 Diabetes Mellitus among cement industry workers. Pak. J. Med. Sci. 2020, 36, 32-36.

23. Majbauddin, A.; Tanimura, C.; Aoto, H.; Otani, S.; Parrenas, M.C.E.; Kobayashi, N.; Morita, T.; Inoue, K.; Masumoto, T.; Kurozawa, Y. Association between dental caries indicators and serum glycated hemoglobin-levels among patients with type 2 diabetes mellitus. J. Oral Sci. 2019, 61, 335-342. [CrossRef]

24. American Diabetes Association. Classification and diagnosis of diabetes: Standards of medical care in diabetes. Diabetes Care 2018, 41, S13-S27. [CrossRef]

25. Sherwani, S.I.; Khan, H.A.; Ekhzaimy, A.; Masood, A.; Sakharkar, M.K. Significance of HbA1c test in diagnosis and prognosis of diabetic patients. Biomark Insights 2016, 11, 95-104. [CrossRef] [PubMed]

26. Ezzati, M.; Riboli, E. Behavioral and dietary risk factors for noncommunicable diseases. New Engl. J. Med. 2013, 369, 954-964. [CrossRef] [PubMed]

27. Paul, L.A.; Burnett, R.T.; Kwong, J.C.; Hystad, P.; van Donkelaar, A.; Bai, L.; Goldberg, M.S.; Lavigne, E.; Copes, R.; Martin, R.V.; et al. The impact of air pollution on the incidence of diabetes and survival among prevalent diabetes cases. Environ. Int. 2019, 134, 105333. [CrossRef] [PubMed] 
28. Liu, F.; Guo, Y.; Liu, Y.; Chen, G.; Wang, Y.; Xue, X.; Liu, S.; Huo, W.; Mao, Z.; Hou, Y.; et al. Associations of long-term exposure to PM1, PM2.5, NO2 with type 2 diabetes mellitus prevalence and fasting blood glucose levels in Chinese rural populations. Environ. Int. 2019, 133, 105213. [CrossRef]

29. Kelsall, H.L.; Fernando, P.H.S.; Gwini, S.M.; Sim, M.R. Cardiovascular disease and type 2 diabetes risk across occupational groups and industry in a statewide study of an Australian working population. J. Occup. Environ. Med. 2018, 60, 286-294. [CrossRef]

30. Yang, A.M.; Cheng, N.; Pu, H.Q.; Liu, S.M.; Li, J.S.; Bassig, B.A. Metal exposure and risk of diabetes and prediabetes among Chinese occupational workers. Biomed. Environ. Sci. 2015, 28, 875-883.

31. Wang, B.; Jing, X.D.; Liu, D.; Yan, S.; Wang, Y. Effect of long-term exposure to air pollution on type 2 diabetes mellitus risk: A systemic review and Metaanalysis of cohort studies. European J. Endocrinol. 2014, 171, $173-182$. [CrossRef]

32. Balti, E.V.; Echouffo-Tcheugui, J.B.; Yako, Y.Y.; Kengne, A.P. Air pollution and risk of type 2 diabetes mellitus: A systematic review and meta-analysis. Diabet. Res. Clin. Pract. 2014, 106, 161-172. [CrossRef]

33. Park, S.K.; Wang, W. Ambient air pollution and Type 2 Diabetes: A Systematic Review of Epidemiologic Research. Curr. Environ. Health Rep. 2014, 1, 275-286. [CrossRef]

34. Eze, I.C.; Hemkens, L.G.; Bucher, H.C.; Hoffmann, B.; Schindler, C.; Künzli, N.; Schikowski, T.; Probst-Hensch, N.M. Association between ambient air pollution and diabetes mellitus in Europe and North America: Systematic review and meta-analysis. Environ. Health Perspect. 2015, 123, 381-389. [CrossRef]

35. Bellou, V.; Belbasis, L.; Tzoulaki, I.; Evangelou, E. Risk factors for type 2 diabetes mellitus: An exposure-wide umbrella review of meta-analyses. PLoS ONE 2018, 13, e0194127. [CrossRef]

36. Sanjay, R.; Robert, D.B. Air pollution and type 2 diabetes. Diabetes 2012, 61, 3037-3045.

37. Krämer, U.; Herder, C.; Sugiri, D.; Strassburger, K.; Schikowski, T.; Ranft, U.; Rathmann, W. Traffic-related air pollution and incident type 2 diabetes: Results from the SALIA cohort study. Environ. Health Perspect. 2010, 118, 1273-1279.

38. Pearson, J.F.; Bachiredd, Y.C.; Shyamprasad, S.; Goldfine, A.B.; Brownstein, J.S. Association between fine particulate matter and diabetes prevalence in the US. Diabetes Care 2010, 33, 2196-2201. [CrossRef]

39. Fabricio, G.; Malta, A.; Chango, A.; De, F., Mathias. Environmental contaminants and pancreatic beta-cells. J. Clin. Res. Pediatr. Endocrinol. 2016, 8, 257-263. [CrossRef] [PubMed] 